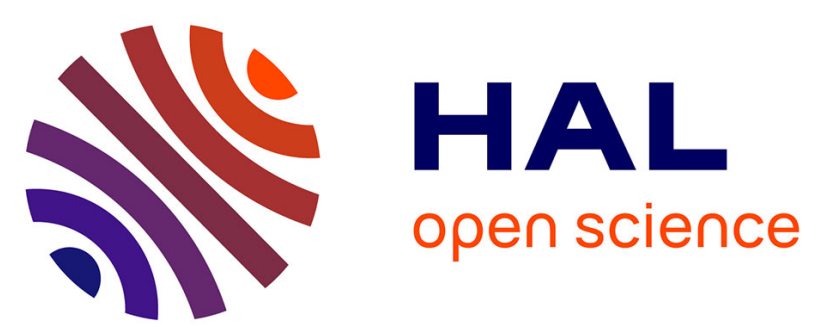

\title{
Boldness and exploration vary between shell morphs but not environmental contexts in the snail Cepaea nemoralis
}

\author{
Maxime Dahirel, Valentin Gaudu, Armelle Ansart
}

\section{- To cite this version: \\ Maxime Dahirel, Valentin Gaudu, Armelle Ansart. Boldness and exploration vary between shell morphs but not environmental contexts in the snail Cepaea nemoralis. Ethology, 2021, 127 (4), pp.321-333. 10.1111/eth.13129 . hal-03127137}

\author{
HAL Id: hal-03127137 \\ https://hal.science/hal-03127137
}

Submitted on 22 Feb 2021

HAL is a multi-disciplinary open access archive for the deposit and dissemination of scientific research documents, whether they are published or not. The documents may come from teaching and research institutions in France or abroad, or from public or private research centers.
L'archive ouverte pluridisciplinaire HAL, est destinée au dépôt et à la diffusion de documents scientifiques de niveau recherche, publiés ou non, émanant des établissements d'enseignement et de recherche français ou étrangers, des laboratoires publics ou privés.

\section{(ㄷ)(1) $\$$}

Distributed under a Creative Commons Attribution - NonCommerciall 4.0 International 


\section{Boldness and exploration vary between shell morphs but not environmental}

\section{2 contexts in the snail Cepaea nemoralis}

3 Running title: Personality and shell morph in snails

4 Maxime Dahirel $^{* 1,2} ;$ Valentin Gaudu $^{1}$; Armelle Ansart $^{1}$

$5 \quad$ *corresponding author: maxime.dahirel@yahoo.fr

$6{ }^{1}$ Univ Rennes, CNRS, ECOBIO (Ecosystèmes, biodiversité, évolution) - UMR 6553, F-35042 Rennes,

7 France

$8{ }^{2}$ INRAE, Université Côte d'Azur, CNRS, ISA, F-06903 Sophia-Antipolis, France

9

\section{Acknowledgments}

11 We thank Youn Henry and Kévin Tougeron for helpful pointers on the link between behavior and thermal tolerance, as well as two anonymous referees and the editor for their comments on previous versions of this article.

The authors have no conflict of interest to declare.

Data accessibility

Data and code
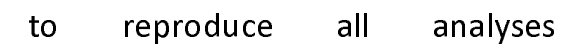

are

available

on

GitHub

(https://github.com/mdahirel/cepaea-personality-2017) and archived in Zenodo (DOI: 


\section{Abstract}

23 Understanding the maintenance of among-individual behavioral variation in populations, and

24 predicting its consequences, are key challenges in behavioral ecology. Studying the association

25 between repeatable behaviors and other traits under selection may shed light on the underlying

26 selective pressures. We used the model snail Cepaea nemoralis to examine whether individual

27 behavior is associated with shell morph, a key trait that has been extensively studied in the context

28 of thermal tolerance and predator avoidance, and which is known to be under strict genetic control

29 in this species. We quantified proxies of boldness and exploration in snails of three morphs coming

30 from two habitats with different thermal contexts. We show that both behaviors were repeatable at

31 the among-individual level (within-state $R_{\text {boldness }}=0.22$ [95\% credible interval: $\left.0.15,0.29\right] ; R_{\text {exploration }}=$

$320.20[0.15,0.25])$. Behavior was associated with shell morph, with the darker morph (five-banded)

33 being consistently shyer and slower to explore. There was no evidence that thermal environment of

34 origin influenced behavior. Snails became faster when test temperature increased; we found no

35 evidence morphs differed in their thermal response. Boldness and exploration were correlated

36 among individuals, forming a syndrome $(r=0.28[0.10,0.46])$. We discuss what these results may tell

37 us about the type of selection exerted by predators. We also detail how our results hint to a genetic

38 link between shell morph and behavior, and the evolutionary implications of such a link. Finally, we

39 discuss how our findings combined with decades of evolutionary research make $C$. nemoralis a very

40 valuable model to study the evolution of behavior in response to environmental changes.

41 Keywords animal personality; behavioral syndromes; Gastropoda; multivariate multilevel model;

42 shell color; temperature 
A key question in behavioral ecology, and more broadly in evolutionary ecology, is how to explain the persistence of variation in phenotypic traits. Although behavior is often seen as highly labile and dynamically adjustable to experienced conditions, individuals of many animal species exhibit "personalities", i.e. behave consistently across time and contexts, and differ consistently from each other (Kralj-Fišer \& Schuett, 2014; Réale, Reader, Sol, McDougall, \& Dingemanse, 2007; Sih, Bell, Johnson, \& Ziemba, 2004). This among-individual variation persists even when better adjustments of behaviors to environmental conditions would be adaptive, and the ability to tune behavior to conditions may itself vary among individuals (variation in "behavioral reaction norms"; Dingemanse, Kazem, Réale, \& Wright, 2010). Moreover, behaviors are often correlated with each other and with other traits, forming multivariate syndromes (Réale et al., 2007; Royauté, Berdal, Garrison, \& Dochtermann, 2018; Santostefano, Wilson, Niemelä, \& Dingemanse, 2017), further constraining the range of behavioral phenotypes that are on display in populations (Dochtermann \& Dingemanse, 2013).

State-dependent behavior is often invoked as one of the key mechanisms/frameworks potentially explaining both adaptive correlations/feedbacks between behaviors and other traits, and the maintenance of among-individual variation (Sih et al., 2015; Wolf \& McNamara, 2012; Wolf \& Weissing, 2010). Individuals can differ in morphology, size, past experienced environment, or any other so-called "state variables", typically less labile than behavior or even fixed at the individual level. If the costs and benefits of behaviors vary depending on these state variables, then we should expect individuals differing in state to adaptively differ in behaviors as well (Wolf \& Weissing, 2010). The pace-of-life hypothesis, which ties several axes of behavioral variation to underlying differences in life history and metabolism along a fast-slow axis (Réale et al., 2010; Wolf \& McNamara, 2012;

66 Wright, Bolstad, Araya-Ajoy, \& Dingemanse, 2019), can be seen under this lens. Other examples

67 include cases of phenotypic compensation, where predation risk can either be mitigated by 
behavioral changes or morphological defenses, leading to a positive association between risk-taking behavior and defenses (e.g. Ahlgren, Chapman, Nilsson, \& Brönmark, 2015; but see De Winter, Ramalho Martins, Trovo, \& Chapman, 2016 for a contradictory example). In some cases, quantitative genetics and/or experimental evolution approaches may provide evidence of the evolution of statebehavior associations (e.g. Kern, Robinson, Gass, Godwin, \& Langerhans, 2016). In other cases in which this may be difficult, we believe that studying the association between personality and state traits can still provide valuable insights, especially if (i) the state trait is known to be fully genetically determined with little to no plasticity, (ii) we are able to study behavioral variation across a range of environments known to select on the state variable.

The grove snail Cepaea nemoralis (Linnaeus 1758) (family Helicidae) is a simultaneous hermaphrodite, medium-sized land gastropod common in western Europe (adult shell diameter 18$25 \mathrm{~mm}$; Welter-Schultes, 2012). It has a long history as a model in evolutionary biology, due to its conspicuous shell polymorphism (reviewed by Jones, Leith, \& Rawlings, 1977; Ożgo, 2009)(Fig. 1A-B). Genetic variation in shell background color (from pale yellow to brown, but usually divided in yellow, pink, and brown; Davison, Jackson, Murphy, \& Reader, 2019) and in the number or width of dark bands has been well described (Jones et al., 1977). Shell polymorphism is governed by a limited number of loci with a limited number of alleles (Richards et al., 2013), and by all evidence shows no phenotypic plasticity. Modern genomics studies now aim to pinpoint the actual molecular/physiological underpinnings of shell color (Kerkvliet, Boer, Schilthuizen, \& Kraaijeveld, 2017; Richards et al., 2013).

In C. nemoralis, lighter-colored shells absorb less heat and allow snails to maintain a lower body temperature (Heath, 1975) and higher water content (Chang, 1991). Many studies have shown that lighter (vs. darker) snails have a selective advantage in hotter/sunnier (vs. colder/shaded) environments, whether one looks at continental-scale latitudinal clines (Jones et al., 1977; Silvertown et al., 2011), local-scale habitat comparisons (Kerstes, Breeschoten, Kalkman, \& Schilthuizen, 2019; 
93 Ozgo \& Kinnison, 2008; Schilthuizen, 2013), or historical comparisons in the context of climate

94 change (Ożgo, Liew, Webster, \& Schilthuizen, 2017; Ożgo \& Schilthuizen, 2012). Local variations in

95 morph frequencies have also been linked to predation pressure, generally in the context of visual

96 selection (frequency-dependent selection and/or crypsis; Jones et al., 1977; Surmacki, Ożarowska-

97 Nowicka, \& Rosin, 2013, and references therein; but see Cook, 2008), but morph differences in shell

98 resistance to crushing have also been described (Rosin, Kobak, Lesicki, \& Tryjanowski, 2013).

Although this has been much less studied, shell morphs also vary in their behavior (Chang, 1991;

Jones, 1982; Ożgo \& Kubea, 2005; Rosin et al., 2018). Part of this variation is likely the direct

consequence of differences in shell thermal properties and thus effective body temperature, as demonstrated by experiments that created "artificial" morphs by painting shells (Tilling, 1983). However, they probably also reflect, at least partly, intrinsic physiological differences: preferred temperatures can be altered using opioid agonists or antagonists, but banded snails are less responsive to this pharmaceutical manipulation (Kavaliers, 1992). Existing studies, however, have several major shortfalls for our understanding of the association between Cepaea morphology and behavioral syndromes. In particular, individuals are generally assayed once, which means separating within- from among-individual variation is impossible (Dingemanse \& Wright, 2020; Niemelä \& Dingemanse, 2018). This also means the level of total among-individual variation, and how it compares with among-morph variation, has remained to our knowledge unstudied. Additionally, all snails are often sampled from the same habitat, or habitat information is not used in behavioral analyses, meaning there is often no way to determine how behavior responds to selection pressures on shell color.

In this context, we investigated the existence and magnitude of personality variation and behavioral syndromes in C. nemoralis, how behavior is linked to shell variation, and how it is influenced by the environment of origin (sun-exposed or shaded) and currently experienced conditions. More 117 specifically, we make the following hypotheses: 
118 (i) Exploration and boldness (risk-taking behavior) are both repeatable in this species, and positively

119 correlated in a behavioral syndrome (Réale et al., 2010).

120 (ii) As boldness may increase predation risk (e.g. Hulthén et al., 2017), we may expect phenotypic

121 compensation through shell characteristics to be present in bolder individuals. This would lead to

122 correlations between morph and behavior, the direction of which providing insights into the

123 dominant selection pressures.

124 (iii) As snails are ectotherms, exploration should increase with temperature due to increased

125 metabolism (over the range of temperatures suitable to movement; Abram, Boivin, Moiroux, \&

126 Brodeur, 2017; Cloyed, Dell, Hayes, Kordas, \& O'Gorman, 2019). We expect this temperature-

127 exploration reaction norm should vary both in its slope and average value according to shell morph

128 and habitat of origin. Populations having evolved in sun-exposed habitats, and lighter (unbanded)

129 snails should be better adapted to maintain activity in the face of high temperatures (e.g. Cloyed et

130 al., 2019), at the possible costs of lower activity at lower temperatures (Tilling, 1983).

\section{Methods}

Snails were sampled in fall 2016 in and close to the village of Arçais, France (Fig. 1C), roughly in the

middle of the recorded latitudinal range of Cepaea nemoralis (GBIF Secretariat, 2020). We studied

two sites located about $2 \mathrm{~km}$ apart and differing in terms of vegetation cover. One was a garden with

few isolated trees, and thus under relatively direct sun exposure all year long (hereafter the "open

habitat"; approximate location: $46^{\circ} 17^{\prime} 50^{\prime \prime} \mathrm{N}, 0^{\circ} 41^{\prime} 30^{\prime \prime} \mathrm{W}$, Fig. 1D). The other was a 200 by $150 \mathrm{~m}$ 
142 with no bands, three bands on the lower side of the shell, and five bands (Fig. 1B). Following previous

143 authors (e.g. Kavaliers, 1992), we here focused for simplicity solely on band presence, and thus

144 sampled only snails with yellow background shells, which are the most common in the study region

145 (Silvertown et al., 2011; personal observations) and on which the contrast between shell background

146 and dark bands is the strongest. We acknowledge that this may prevent us from fully generalizing, for

147 now, to natural populations, as the effect of darker background color is not always the same as the

148 effect of increased shell banding (e.g. Kerstes et al., 2019). Snails were hand-collected during the day,

149 their period of inactivity, both by simplicity and to avoid skewing our sample towards more active

150 individuals. If there were nonetheless a bias towards catching more conspicuous/ less likely to hide

151 snails, we believe it would have artificially reduced, rather than increased, our effect sizes: we would

152 have sampled the most active morph and the most active individuals from the least active morph,

153 reducing mean morph differences.

154 Sampling for the present study was targeted and adjusted in the field to obtain roughly equal

155 numbers of each banding pattern from both landscapes; it therefore did not allow us to make inferences on their relative abundances. The same sites were however sampled again in 2018 for a separate experiment, this time with random sampling relative to banding pattern. As in previous studies (e.g. Schilthuizen, 2013) and reflecting potential thermal selection, the darker five-banded snails were more frequent in the shaded habitat than in the open habitat ( 22.3 vs. $13.5 \%$; see Supplementary Material S1).

We transferred snails to the lab and kept them under dormancy conditions $\left(6 \pm 1^{\circ} \mathrm{C}\right.$, no light, food or water sources) until March 2017, about 3 weeks before the start of the experiment. We then divided them into groups of 15 individuals from the same landscape, five (randomly chosen) of each shell phenotype. Comparing group size to natural densities is difficult, due to the way natural densities are often reported in the literature (averages over entire habitats, including empty areas). However, 
167 used in experiments (Oosterhoff, 1977; Rosin et al., 2018; Wolda, 1967). Groups were kept under

168 controlled conditions $\left(20 \pm 1^{\circ} \mathrm{C}, \mathrm{L}: \mathrm{D} 16: 8\right)$ in $8.5 \times 15 \times 12 \mathrm{~cm}$ polyethylene boxes lined with $1-2 \mathrm{~cm}$ of

169 soil kept humid at the bottom. Snails had ad libitum access to prepared snail food (cereal flour

170 supplemented with calcium, Hélinove, Saint Paul en Pareds, France) in a Petri dish. We gave each

171 snail a unique ID written on the side of their shell with a paint marker (uni Posca, Mitsubishi Pencil

172 Co., Ltd, Tokyo, Japan; Henry \& Jarne, 2007). A total of 360 snails (60 for each habitat $\times$ shell

173 phenotype combination) were used in the experiments described below. By necessity, the observer

174 (see below) was not blind to individual habitat of origin/phenotype; note that the analyst (MD) did not contribute to the actual observations.

We studied boldness using simulated predator attacks as in Dahirel et al. (2017). All tests were done period. Like other helicids, Cepaea nemoralis is nocturnal but tends to start activity sometime before dark (Cameron, 1970). To stimulate activity, we first placed them in a Petri dish with water for 5 minutes, before putting them on individual clean glass plates. After snails had moved at least one shell length $(\approx 20 \mathrm{~mm})$ from their starting position, the operator used a pipette tip to pinch them for 5 seconds on the right side of the foot. Preliminary tests confirmed that this was the shortest time needed to ensure all snails retracted fully in their shell. We then recorded the time snails took to exit the shell and resume activity after the attack (from retraction to the full extension of all tentacles out of the shell), as our measure of boldness (snails with shorter latencies being considered bolder). We stopped observations after $20 \mathrm{~min}$ if snails did not exit the shell. Snails from the same test box were 
191 order in which groups were tested within a sequence was random; this order was conserved for all

192 subsequent tests.

194 We studied snail movement at four temperatures within the activity range of $C$. nemoralis (Cameron,

195 1970): $15,18,22$, and $25^{\circ} \mathrm{C}$. All tests were again performed by the same operator (VG), and again

196 during the last four hours of the photophase each day. Movement tests started 7 days after the last boldness test for a given individual, successive movement tests were separated by $24 \mathrm{~h}$. Half of the boxes, equally distributed between landscapes of origin, were tested in increasing temperature order (from 15 to $25^{\circ} \mathrm{C}$ ), the other half in decreasing order $\left(25^{\circ} \mathrm{C}\right.$ to $\left.15^{\circ}\right)$. Twenty-four hours before a given test, we placed snails and their rearing box at the testing temperature for habituation, using was placed individually at the center of a clean $25 \times 25 \mathrm{~cm}$ polyethylene box (height: $9 \mathrm{~cm}$ ) and left free to move. Snails were deemed active once they had moved more than $2 \mathrm{~cm}$ away from their starting point. We used the time snails took to move more than $10 \mathrm{~cm}$ from their starting point, minus the time taken to start activity, as our exploration metric (with lower values for snails that moved away faster). We stopped observations after 20 min post-activity initiation. This metric was chosen for its ease of implementation; we acknowledge that it conflates exploration of the environment with movement speed (as both slow-moving individuals and thorough explorers would have higher first-passage times).

This study complies with all relevant national and international laws, and the ASAB/ABS Guidelines

212 for the use of animals (2020) were adhered to as closely as possible. Potentially stressful 213 experimental treatments (boldness experiment) were limited to the shortest possible time to elicit 214 the behaviors of interest. No ethical board recommendation or administrative authorization was 215 needed to work on or sample Cepaea nemoralis. The marking method used is non-invasive and has 
216 minimal to no documented effects on life-history traits (Henry \& Jarne, 2007). We do not believe

217 there is any potential for bias due to social background, self-selection, experience or other factors

218 indicated in the STRANGE framework (Webster \& Rutz, 2020). To the best of our knowledge, the

219 studied individuals are representative of the local populations studied, except for the two constraints

220 explicitly imposed on collection by our experimental design (only adults, equal numbers of a few

221 morphs of interest). All individuals were subjected to the same experimental conditions once

222 collected.

Statistical analyses

We analyzed snail behavioral data in a Bayesian multilevel/mixed model framework, using the Stan

Betancourt, \& Gelman, 2019; Kay, 2019; Pedersen, 2019; Wickham et al., 2019).

We used a bivariate generalized linear multilevel model to estimate the effect of shell phenotype, habitat and temperature on behavior, quantify behavioral (co)variances and partition them across hierarchical levels (among-box, among-individual and within-individual variation) (Dingemanse \&

Dochtermann, 2013; Houslay \& Wilson, 2017). We did not estimate within-individual trait

correlations, as exploration and boldness were tested independently at the within-individual level

(that is, boldness measure 1 had no stronger "link" to exploration measure 1 than boldness measure

2; scenario 4 of table 2 in Dingemanse \& Dochtermann, 2013). We present a full write-up of the model as Supplementary Material S2; a general description follows below.

Boldness and exploration were analyzed assuming a lognormal distribution to account for the skewed distribution of time to event data. We accounted for the fact that monitoring was stopped before some individuals could express the behavior of interest by including a censored data indicator 
241 variable), landscape of origin (binary variable), and their interaction, as well as test order (1 or 2 for

242 boldness, 1 to 4 for exploration). The model for exploration additionally included a test temperature

243 effect as well as its interactions with shell banding and landscape. Categorical variables (shell

244 banding, landscape of origin) were converted to centered dummy variables, and numeric variables

245 (test order, temperature) were centered, following Schielzeth (2010)(temperature was additionally

246 scaled to unit 1SD). This has two benefits. First, it makes main effect coefficients directly

247 interpretable even in the presence of interactions (Schielzeth, 2010). Second, for categorical

248 variables, having the intercept on an "average" rather than on one arbitrary default category avoids

249 the problem of putting a more precise prior on an arbitrary reference category (which would be

250 defined by the intercept only) than on the others (which would be defined by the intercept and one

or several other coefficients)(McElreath, 2020). Morph-specific coefficients (intercepts, slopes)

remain easy to obtain post-fitting, by simply adding the relevant posterior coefficients. Random

effects included box-level and individual-level intercepts as well as, in the case of exploration, the

associated slopes for temperature. This allowed us to estimate among-box and among-individual

variation in mean behavior and thermal behavioral reaction norms as well as the box- and individual-

level covariances among them (Dingemanse \& Dochtermann, 2013).

We used a Normal $(\mu=\ln (400), \sigma=0.5)$ prior for the fixed effects intercepts (mean log- latencies), so

that $\sim 99 \%$ of the probability mass was within the range of latencies that was observable during the

experiment (i.e. 0 to $1200 \mathrm{sec}$, see above), but not excluding larger values, because of censoring. We

set the other priors to be weakly informative and follow some suggestions by McElreath (2020): a

Normal $(0,1)$ prior for the other fixed effects, a half-Normal $(0,1)$ prior for both random effect and 
266 We partitioned total phenotypic variation $V_{P}$ for each behavior into the following components: $V_{P}=$

$267 \quad V_{F}+V_{I}+V_{B}+V_{D}$, where $V_{F}$ is the fixed effect variation, including $V_{F(\text { state })}$ the portion of fixed-effect

268 variance attributable to known individual state (banding pattern, environment of origin), i.e.

269 excluding experimental effects (test order, temperature) (estimated following de Villemereuil,

270 Morrissey, Nakagawa, \& Schielzeth, 2018); $V$, the average among-individual variation (including the

271 effect of random temperature slope, estimated following Johnson, 2014), with $V_{\text {l(intercept) }}$ the among-

272 individual variation at the average test temperature $\left(V_{l}=V_{l(\text { intercept })}\right.$ for boldness); $V_{B}$ and $V_{B \text { (intercept) }}$ are

273 the equivalent box-level variances; and $V_{D}$ is the distributional, or residual, variation. As pointed by

274 Wilson (2018) and de Villemereuil et al. (2018), there is in most cases no one "true" repeatability

275 estimate just as there is no one "true" way of partitioning the phenotypic variance pie; several

276 estimates with differing interpretations can be presented. Therefore, both absolute variance

277 components and analytical choices regarding repeatabilities should be made explicit. We estimated

278 the following two unadjusted repeatabilities (i.e. including the entirety of $V_{p}$ in the denominator;

279 Nakagawa \& Schielzeth, 2010): within-state repeatability $R_{\text {(within-state) }}=V_{\text {l(intercept) }} / V_{p}$, and what we

280 term total repeatability, $R_{(\text {total })}=\left(V_{l(\text { (intercept) }}+V_{F(\text { state) }}\right) / V_{p}$. The proportion of persistent among-

281 individual variation that is attributable to individual state (banding and landscape of origin) is then

282 denoted by $V_{F(\text { state) }} /\left(V_{\text {l(intercept })}+V_{F(\text { state) }}\right)$. Variance components and repeatabilities are presented on

283 the observed data scale (sensu de Villemereuil, Schielzeth, Nakagawa, \& Morrissey, 2016). Variance

284 components on the latent log scale (i.e. directly using model coefficients) led to qualitatively and

285 quantitatively similar results.

286 We ran four chains for 12000 iterations, with the first 2000 iterations of each chain used for warmup.

287 We checked mixing graphically and confirmed chain convergence using the improved $\widehat{R}$ statistic by

288 Vehtari et al. (2020). The chains were run longer than the default number of iterations to ensure the

289 effective sample size was satisfactory for all parameters (both bulk- and tail-effective sample sizes

290 sensu Vehtari et al., 2020 at least $>400$, here $>1000$ ). All posterior summaries are given as mean

291 [95\% highest posterior density interval]. 
292

293

294

295

296

297

298

299

300

301

302

303

304

305

306

307

308

309

310

311

312

313

314

315

316

\section{Results}

Exploration was related to shell morph (Table 1, Fig. 2), with morph-specific intercepts, i.e. mean loglatencies, for 0,3 and 5-banded snails of $6.65[6.59,6.69], 6.64[6.59,6.69]$ and $6.71[6.66,6.76]$, respectively. Five-banded snails were on average slower to explore their surroundings than either three-banded or unbanded snails (in both cases, mean difference: 0.07 [0.01, 0.13])(Fig.2) Snails also became slower as tests went on (Table 1). We found no clear evidence of an effect of the landscape of origin on exploration. Snails explored faster with increasing temperature (Table 1, Fig. 2; temperature slopes for 0,3 , and 5-banded snails: $-0.12[-0.16,-0.07],-0.11[-0.16,-0.07],-0.10[-$ $0.15,-0.06])$. There was however no clear evidence that the slope of the temperature reaction norm varied between the three morphs, or between snails coming from different landscapes (Table 1; credible intervals for all interactions largely overlap 0$)$.

Morphs also varied in average boldness (Table 1, Fig. 2), with morph-specific intercepts for 0,3 and 5-banded snails of $2.84[2.65,3.04], 2.99[2.79,3.18]$ and $3.10[2.90,3.30]$, respectively. Unbanded snails were bolder than five-banded snails (mean difference: $-0.26[-0.47,-0.05]$ ); three-banded snails presenting intermediate values, with no clear difference with either extreme morph. Again, there was no evidence for landscape or landscape $\times$ morph effects.

Both exploration and boldness were repeatable at the individual level, with average repeatabilities in the same range for both behaviors (Table 2). Including fixed effect variation due to individual state (morph and landscape of origin) in the calculation only slightly increased repeatabilities. Indeed, the proportion of persistent among-individual variation attributable to fixed effects was different from zero but small, with over $90 \%$ of individual-level variation attributable to other, unmeasured sources

(Fig. 3, Table 2). Among-individual variation in temperature slopes was minimal, with variation in intercepts explaining $98 \%$ [89\%, 100\%] of the average exploration $V_{l}$ (Fig. 3, Table 2). Accordingly, we find no clear evidence that the level of among-individual variation changes across the temperature gradient; following equations in Brommer (2013), the ratio between latent-scale $V_{1}$ at the lowest and 
317 highest tested temperatures is not different from $1(0.76[0.39,1.13])$. We also found no evidence of

318 widespread rank switching across the temperature gradient (faster than average individuals in one

319 environment remained overall faster across contexts): indeed, the cross-environmental correlation,

320 which is higher the more predicted individual rankings stay consistent across environmental

321 gradients (Brommer, 2013), was close to 1 when comparing the two extremes of the thermal

322 gradient $(0.85[0.62,1.00]$ on the latent scale).

Variation among boxes was small but non-negligible, in the same range as the proportion of variation explained by fixed effects for both behaviors. Average exploration and boldness were positively

correlated at the individual level (Table 3, Fig. 4). There was no evidence that among-individual variation in responses to temperature was correlated with either mean exploration times or mean boldness (Table 3). There was no evidence for box-level correlations among traits (Table 3).

Discussion

By showing that behaviors linked to boldness and exploration are repeatable in Cepaea nemoralis, we add to a growing list of personality studies in gastropods, highlighting the usefulness of this taxon to address key questions in behavioral ecology (see e.g. Ahlgren et al., 2015; Cornwell, McCarthy, \& Biro, 2020; Cornwell, McCarthy, Snyder, \& Biro, 2019; Dahirel et al., 2017; Goodchild, Schmidt, \& DuRant, 2020; Seaman \& Briffa, 2015). We note however that this list is biased towards freshwater and marine gastropods; more studies are needed to understand among-individual variation in behavior in land mollusks. Additionally, we demonstrated that boldness and exploration are positively correlated in a common syndrome and that their expression varies depending on shell banding, a trait under strictly genetic determinism (little to no plasticity) that has been the focus of a 
342 Unbanded snails were both bolder and explored faster than five-banded snails (Table 1, Fig. 2).

343 Three-banded snails behaved similarly to unbanded snails for exploration (but were intermediate

344 between unbanded and five-banded snails for boldness). This shows the "effectively unbanded"

345 category sometimes used in Cepaea studies (Cain \& Sheppard, 1954; Ożgo \& Schilthuizen, 2012) has

346 at least some behavioral relevance (that category groups together snails with little to no banding on

347 the side of their shell exposed to the sun). Exploration and boldness were positively correlated both

348 at the among-individual (Table 2) and among-morph levels (the shyest morph was also the slowest,

349 Fig. 2). At the individual level, while some clutches were laid during the experiments, we were not

350 able to test if this behavioral syndrome was integrated into a broader pace of life syndrome sensu

351 Réale et al. (2010) by linking behavioral and life-history variation. Indeed, we were unable to

352 ascertain the maternal and especially paternal origin of most clutches, and were not able to follow

353 snail fecundity or longevity over their entire life. There are however some indications in the literature

354 that more active/mobile snails are faster-growing (Oosterhoff, 1977), as the pace-of-life syndrome

355 hypothesis would predict.

356 Five-banded snails were on average shyer than unbanded snails (Fig. 2). Birds, thrushes in particular

357 (genus Turdus), are key predators of Cepaea nemoralis (Rosin, Lesicki, Kwieciński, Skórka, \&

358 Tryjanowski, 2017; Rosin, Olborska, Surmacki, \& Tryjanowski, 2011). Historically, both frequency-

359 dependent predation and direct visual selection due to crypsis have been invoked as explanations for

360 predator-dependent morph variation in Cepaea (Jones et al., 1977; Ożgo, 2009), but discussions

361 often used human vision as a baseline. More recently, crypsis explanations have received increased

362 support from an experiment using models of avian vision to more rigorously test how thrushes see

363 different shell morphs (Surmacki et al., 2013). In both our test sites, the boldest morph (unbanded

364 shell) is the least conspicuous (based on Surmacki et al., 2013), not the rarest. Building on the

365 phenotypic compensation hypothesis (i.e. that risk-taking individuals should be better defended;

366 Ahlgren et al., 2015; Kuo, Irschick, \& Lailvaux, 2015), this result then adds support to crypsis-based

367 explanations of Cepaea morph variation. However, phenotypic compensation is not a hard rule, and 
risk-taking individuals are sometimes less defended than risk-avoiding ones (De Winter et al., 2016;

Goodchild et al., 2020). Besides, snails are also predated by rodents (Rosin et al., 2011), and shell morphs differ in shell strength in ways that go counter to the phenotypic compensation hypothesis

371 (5-banded shells being stronger; Rosin et al., 2013). The combined effect of color and shell thickness/strength on predation risk remains to be studied. Finally, we must remember that (i) our knowledge of how avian predators perceive snails is very limited (Surmacki et al., 2013), (ii) we only tested a small set of the available morphs, which do not include the rarest background colors (pink and brown), and (iii) shell banding is a trait under multiple selection pressures, including thermal selection (see below).

Exploration speed was temperature-dependent: as expected from an ectothermic species, snails were on average faster at higher temperatures (Fig. 2). The temperature reaction norm of exploration was remarkably conserved among individuals (the near-totality of the among-individual variance $V_{/}$was due to differences in average behavior, rather than in temperature slopes; Table 2,

Fig. 3). In addition, there was surprisingly no evidence that behavioral differences among morphs are influenced by the thermal environment, whether we consider the environment of origin (no habitat $x$ morph interaction) or the current environment (no effect of morph identity on thermal reaction norms) (Table 1). This is despite abundant evidence in the literature for thermal selection on shell morphs, based on both field comparisons (e.g. Richardson, 1974; Schilthuizen, 2013; Kerstes et al., 2019; for this study, see Methods), and experiments (Lamotte, 1959; Tilling, 1983; Wolda, 1967).

Studies giving snails a choice between multiple temperatures show snail morphs do have different thermal preferences that align with expectations based on thermal selection (Kavaliers, 1992). Some studies suggest that snails use shade and humidity just as much (and potentially more) as 
394 (including shade and/or humidity) would yield different responses. Maybe more importantly, we only

395 tested temperatures favorable for activity, i.e. the limited part of the thermal niche closer to the

396 optimum. Morph differences in behavior might be stronger closer to critical minimal or maximal

397 temperature thresholds (Tilling, 1983). This can be investigated by using a wider range of

398 temperatures and expanding the reaction norm approach used here to either a character state

399 approach (e.g. Houslay, Earley, Young, \& Wilson, 2019) or a non-linear reaction norm approach

400 (Arnold, Kruuk, \& Nicotra, 2019); both would account for the typical non-linearity of complete

401 thermal performance curves (Arnold et al., 2019). It is very important to note, however, that these

402 results do not mean populations from landscapes differing in sun exposure are identical in behavior,

403 even for the range of situations we tested. Indeed, because morphs differ in their behavior, and

404 because morph frequencies differ among landscapes (see Supplementary Material S1), the average

405 snail from a sun-exposed population may well be bolder and more active than its counterpart from a

406 shaded population.

407 In any case, the links between behaviors and morphs we observed are conserved across contexts,

408 despite (apparent) selection on shell morph. While this is not a definite proof by itself, we consider

409 this a first hint in favor of a genetic association between morphs and behaviors that cannot be easily

410 broken by environmental changes. In addition to studies aiming to confirm these behavioral traits are

411 heritable, further research into the physiological underpinnings of behavioral differences between

412 morphs (building on e.g. Kavaliers, 1992) and of shell color and pattern determination (Kerkvliet et

413 al., 2017) should help confirm (or infirm) this putative genetic correlation and elucidate its proximate

414 basis.

415 Assuming this genetic link is confirmed, any discussion about how selection on morph may influence

416 the evolution of behavior (or vice versa) must be tempered by one fact: the greater part of the

417 repeatable among-individual variation in behavior was not explained by shell morph (see Fig. 3, Table

418 1, and the fact that morph differences are hard to see from raw data in Fig. 2). It is in a way 
419 unsurprising, as we did not expect a single discrete trait to entirely constrain individual behavioral

420 variation. Indeed, the expression of animal personalities can be influenced by many unobserved

421 drivers and state variables which should have a priori limited links to shell morph and its drivers

422 (Burns et al., 2012; Petelle, Martin, \& Blumstein, 2019; Sih et al., 2015; Wright et al., 2019). This

423 includes for instance sex or reproductive history (DiRienzo \& Aonuma, 2017; Kralj-Fišer, Hebets, \&

424 Kuntner, 2017), predation risk (Goodchild et al., 2020), age or life stage (Dahirel et al., 2017), or body

425 size (Santostefano et al., 2017). Snail behavior is particularly sensitive to population density including

426 during development (Cameron \& Carter, 1979; Oosterhoff, 1977), an environmental axis we ignored

427 in the present study. Also, our study focused on relatively short-term repeatability; it is possible that

over larger time scales, the variance component related to morph differences plays a more

important role. In a fish community, for instance, some differences among species are detectable

over long but not short time scales (Harrison et al., 2019). Finally, some level of stochastic behavioral

individuality is inevitable even in the total absence of meaningful genetic and environmental 
445 Increased boldness and exploration have been tied to a higher probability of dispersal in many

446 species (Cote, Clobert, Brodin, Fogarty, \& Sih, 2010), including land snails (Dahirel et al., 2017), and

447 non-random dispersal is now acknowledged as a potentially widespread force behind population

448 phenotypic divergence (Edelaar \& Bolnick, 2012; Jacob, Bestion, Legrand, Clobert, \& Cote, 2015).

449 Bolder animals are often thought to trade increased success against a greater predation risk (Hulthén

450 et al., 2017; but see Moiron, Laskowski, \& Niemelä, 2020); predation is generally considered a key

451 driver of morphological differences in Cepaea, and plays a key role in dispersal across taxa (Fronhofer

452 et al., 2018). Although active dispersal can safely be dismissed as a driver of continental-scale

453 differences in morph frequencies, our results point to Cepaea as a good model to understand how

454 existing behavioral differences may drive local-scale morphological differences (and vice versa). By

455 building on, and complementing, a decades-long history of evolutionary research, this will help us

456 better understand the role of behavior, and constraints on behavioral variation, in shaping responses

457 to rapid environmental changes (Candolin \& Wong, 2012), including landscape alteration and climate 458 change.

459

460

461

462

463

464

465

466

467

468

\section{References}

Abram, P. K., Boivin, G., Moiroux, J., \& Brodeur, J. (2017). Behavioural effects of temperature on ectothermic animals?]: Unifying thermal physiology and behavioural plasticity. Biological Reviews, 92(4), 1859?1876. doi: 10.1111/brv.12312

Ahlgren, J., Chapman, B. B., Nilsson, P. A., \& Brönmark, C. (2015). Individual boldness is linked to protective shell shape in aquatic snails. Biology Letters, 11(4), 20150029. doi: $10.1098 /$ rsbl.2015.0029

Arnold, P. A., Kruuk, L. E. B., \& Nicotra, A. B. (2019). How to analyse plant phenotypic plasticity in response to a changing climate. New Phytologist, 222(3), 1235?1241. doi: 10.1111/nph.15656 
469

$A S A B, \& A B S$. (2020). Guidelines for the treatment of animals in behavioural research and teaching. Animal Behaviour, 159, I]XI. doi: 10.1016/j.anbehav.2019.11.002

Bierbach, D., Laskowski, K. L., \& Wolf, M. (2017). Behavioural individuality in clonal fish arises despite near-identical rearing conditions. Nature Communications, 8,15361 . doi: $10.1038 /$ ncomms15361

Brommer, J. E. (2013). Variation in plasticity of personality traits implies that the ranking of personality measures changes between environmental contexts[?]: Calculating the crossenvironmental correlation. Behavioral Ecology and Sociobiology, 67(10), 1709]1718. doi: $10.1007 / \mathrm{s} 00265-013-1603-9$

Bürkner, P.-C. (2017). brms[?]: An R package for Bayesian multilevel models using Stan. Journal of Statistical Software, 80(1), 1?28. doi: 10.18637/jss.v080.i01

Burns, J. G., Svetec, N., Rowe, L., Mery, F., Dolan, M. J., Boyce, W. T., \& Sokolowski, M. B. (2012). Gene-environment interplay in Drosophila melanogaster?]: Chronic food deprivation in early life affects adult exploratory and fitness traits. Proceedings of the National Academy of Sciences of the United States of America, 109(Suppl 2), 17239?17244. doi: 10.1073/pnas.1121265109

Cain, A. J., \& Sheppard, P. M. (1954). Natural selection in Cepaea. Genetics, 39(1), 890116.

Cameron, R. A. D. (1970). The effect of temperature on the activity of three species of helicid snail (Mollusca?]: Gastropoda). Journal of Zoology, 162(3), 303길. doi: 10.1111/j.14697998.1970.tb01267.x

Cameron, R. A. D., \& Carter, M. A. (1979). Intra- and interspecific effects of population density on growth and activity in some helicid land snails (Gastropoda??: Pulmonata). Journal of Animal Ecology, 48(1), 237?246. doi: 10.2307/4111

Candolin, U., \& Wong, B. B. M. (Éds.). (2012). Behavioural responses to a changing world[]: Mechanisms and consequences (1st edition). Oxford: Oxford University Press. 
494 Carpenter, B., Gelman, A., Hoffman, M. D., Lee, D., Goodrich, B., Betancourt, M., ... Riddell, A. (2017).

495 Stan[?]: A probabilistic programming language. Journal of Statistical Software, 76(1), 1 ?32.

496 doi: $10.18637 /$ jss.v076.i01

497 Chang, H.-W. (1991). Activity and weight loss in relation to solar radiation in the polymorphic land

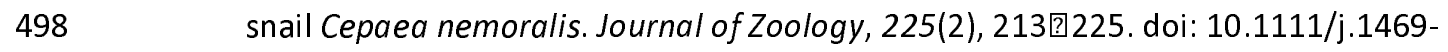

499 7998.1991.tb03812.x

500 Cloyed, C. S., Dell, A. I., Hayes, T., Kordas, R. L., \& O’Gorman, E. J. (2019). Long-term exposure to

501 higher temperature increases the thermal sensitivity of grazer metabolism and movement.

502 Journal of Animal Ecology, O(0). doi: 10.1111/1365-2656.12976

503 Cook, L. M. (2008). Variation with habitat in Cepaea nemoralis?]: The Cain \& Sheppard diagram.

$504 \quad J o u r n a l$ of Molluscan Studies, 74(3), 2390243. doi: 10.1093/mollus/eyn011

505 Cornwell, T. O., McCarthy, I. D., \& Biro, P. A. (2020). Integration of physiology, behaviour and life

506 history traits?]: Personality and pace of life in a marine gastropod. Animal Behaviour, 163,

507 1550162. doi: 10.1016/j.anbehav.2020.03.009

508 Cornwell, T. O., McCarthy, I. D., Snyder, C. R. A., \& Biro, P. A. (2019). The influence of environmental

509 gradients on individual behaviour?: Individual plasticity is consistent across risk and

510 temperature gradients. Journal of Animal Ecology, 88(4), 511国520. doi: 10.1111/1365-

$511 \quad 2656.12935$

512 Cote, J., Clobert, J., Brodin, T., Fogarty, S., \& Sih, A. (2010). Personality-dependent dispersal[?]:

513 Characterization, ontogeny and consequences for spatially structured populations.

514 Philosophical Transactions of the Royal Society of London B: Biological Sciences, 365(1560),

515 406504076. doi: 10.1098/rstb.2010.0176

516 Dahirel, M., Vong, A., Ansart, A., \& Madec, L. (2017). Individual boldness is life stage-dependent and

517 linked to dispersal in a hermaphrodite land snail. Ecological Research, 32, 7510755. doi:

$518 \quad 10.1007 /$ s11284-017-1484-x 
519 Davison, A., Jackson, H. J., Murphy, E. W., \& Reader, T. (2019). Discrete or indiscrete? Redefining the

520 colour polymorphism of the land snail Cepaea nemoralis. Heredity, 1. doi: 10.1038/s41437-

$521 \quad$ 019-0189-z

522 De Winter, G., Ramalho Martins, H., Trovo, R. A., \& Chapman, B. B. (2016). Knights in shining armour

523 are not necessarily bold?]: Defensive morphology correlates negatively with boldness, but

524 positively with activity, in wild threespine stickleback, Gasterosteus aculeatus. Evolutionary

$525 \quad$ Ecology Research, 17, 1912.

Dingemanse, N. J., \& Dochtermann, N. A. (2013). Quantifying individual variation in behaviour[?: Mixed-effect modelling approaches. Journal of Animal Ecology, 82(1), 390154. doi: $10.1111 / 1365-2656.12013$

Dingemanse, N. J., Kazem, A. J., Réale, D., \& Wright, J. (2010). Behavioural reaction norms?]: Animal personality meets individual plasticity. Trends in Ecology \& Evolution, 25(2), 81989. doi: 10.1016/j.tree.2009.07.013

Dingemanse, N. J., \& Wright, J. (2020). Criteria for acceptable studies of animal personality and behavioural syndromes. Ethology, 126(9), 865?869. doi: 10.1111/eth.13082

DiRienzo, N., \& Aonuma, H. (2017). Individual differences are consistent across changes in mating status and mediated by biogenic amines. Behavioral Ecology and Sociobiology, 71(8), 118.

Dochtermann, N. A., \& Dingemanse, N. J. (2013). Behavioral syndromes as evolutionary constraints.

Edelaar, P., \& Bolnick, D. I. (2012). Non-random gene flow?: An underappreciated force in evolution and ecology. Trends in Ecology \& Evolution, 27(12), 659?665. doi:

542 Fronhofer, E. A., Legrand, D., Altermatt, F., Ansart, A., Blanchet, S., Bonte, D., ... Cote, J. (2018).

543 Bottom-up and top-down control of dispersal across major organismal groups. Nature

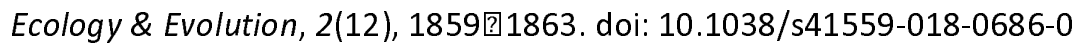


545 Gabry, J., Simpson, D., Vehtari, A., Betancourt, M., \& Gelman, A. (2019). Visualization in Bayesian

546 workflow. Journal of the Royal Statistical Society: Series A (Statistics in Society), 182(2),

547 389]402. doi: $10.1111 /$ rssa.12378

548 GBIF Secretariat. (2020). Cepaea nemoralis (Linnaeus, 1758) in GBIF Backbone Taxonomy. Checklist

549 dataset accessed via GBIF.org on 2020-08-11. Consulté à l'adresse

$550 \quad$ https://doi.org/10.15468/39omei

Gonzalez, D. R., Aramendia, A. C., \& Davison, A. (2019). Recombination within the Cepaea nemoralis supergene is confounded by incomplete penetrance and epistasis. Heredity, 1. doi: $10.1038 / \mathrm{s} 41437-019-0190-6$

Goodchild, C. G., Schmidt, L. M., \& DuRant, S. E. (2020). Evidence for the 'behavioural character' hypothesis?]: Does boldness programme disparate antipredator strategies? Animal

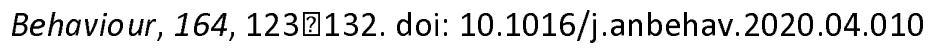

Harrison, P. M., Keeler, R. A., Robichaud, D., Mossop, B., Power, M., \& Cooke, S. J. (2019). Individual differences exceed species differences in the movements of a river fish community. Behavioral Ecology, arz076. doi: 10.1093/beheco/arz076

Heath, D. J. (1975). Colour, sunlight and internal temperatures in the land-snail Cepaea nemoralis (L.). Oecologia, 19(1), 29038. doi: 10.1007/BF00377587

Henry, P.-Y., \& Jarne, P. (2007). Marking hard-shelled gastropods?]: Tag loss, impact on life-history

Houslay, Thomas M., \& Wilson, A. J. (2017). Avoiding the misuse of BLUP in behavioural ecology. 
570 Hulthén, K., Chapman, B. B., Nilsson, P. A., Hansson, L.-A., Skov, C., Brodersen, J., ... Brönmark, C.

571 (2017). A predation cost to bold fish in the wild. Scientific Reports, 7(1), 1239. doi:

$572 \quad 10.1038 / s 41598-017-01270-w$

573 Jacob, S., Bestion, E., Legrand, D., Clobert, J., \& Cote, J. (2015). Habitat matching and spatial

574 heterogeneity of phenotypes[?: Implications for metapopulation and metacommunity

575 functioning. Evolutionary Ecology, 29(6), 851?871. doi: 10.1007/s10682-015-9776-5

576 Johnson, P. C. D. (2014). Extension of Nakagawa \& Schielzeth's $R_{\text {GLMM }}^{2}$ to random slopes models.

577 Methods in Ecology and Evolution, 5(9), 9440946. doi: 10.1111/2041-210X.12225

Jones, J. S. (1982). Genetic differences in individual behaviour associated with shell polymorphism in the snail Cepaea nemoralis. Nature, 298(5876), 749?750. doi: 10.1038/298749a0

Jones, J. S., Leith, B. H., \& Rawlings, P. (1977). Polymorphism in Cepaea?: A problem with too many solutions? Annual Review of Ecology and Systematics, 8, 109?143. JSTOR. Consulté à I'adresse JSTOR.

Kavaliers, M. (1992). Opioid systems, behavioral thermoregulation and shell polymorphism in the land snail, Cepaea nemoralis. Journal of Comparative Physiology B, 162(2), 172?178. doi: 10.1007/BF00398344

Kay, M. (2019). tidybayes?: Tidy data and geoms for Bayesian models. doi: 10.5281/zenodo.1308151

Kerkvliet, J., Boer, T. de, Schilthuizen, M., \& Kraaijeveld, K. (2017). Candidate genes for shell colour polymorphism in Cepaea nemoralis. PeerJ, 5, e3715. doi: 10.7717/peerj.3715

Kern, E. M. A., Robinson, D., Gass, E., Godwin, J., \& Langerhans, R. B. (2016). Correlated evolution of personality, morphology and performance. Animal Behaviour, 117, 79?86. doi: 10.1016/j.anbehav.2016.04.007

Kerstes, N. A. G., Breeschoten, T., Kalkman, V. J., \& Schilthuizen, M. (2019). Snail shell colour evolution in urban heat islands detected via citizen science. Communications Biology, 2(1), 264. doi: $10.1038 / s 42003-019-0511-6$ 
595 Kralj-Fišer, S., Hebets, E. A., \& Kuntner, M. (2017). Different patterns of behavioral variation across

596 and within species of spiders with differing degrees of urbanization. Behavioral Ecology and

597 Sociobiology, 71(8), 125. doi: 10.1007/s00265-017-2353-x

598 Kralj-Fišer, S., \& Schuett, W. (2014). Studying personality variation in invertebrates?]: Why bother?

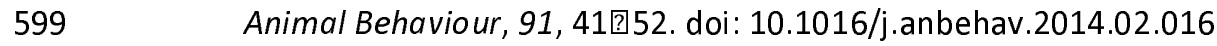

600 Kuo, C.-Y., Irschick, D. J., \& Lailvaux, S. P. (2015). Trait compensation between boldness and the

601 propensity for tail autotomy under different food availabilities in similarly aged brown anole

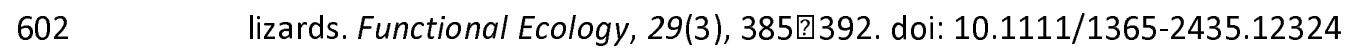

603 Lamotte, M. (1959). Polymorphism of natural populations of Cepaea nemoralis. Cold Spring Harbor

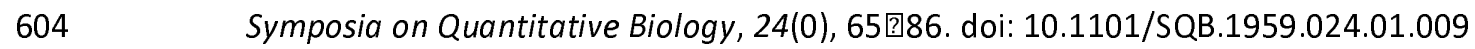

605

McElreath, R. (2020). Statistical rethinking?: A Bayesian course with examples in R and Stan (2nd

606 edition). Boca Raton, USA: Chapman and Hall/CRC.

607 Moiron, M., Laskowski, K. L., \& Niemelä, P. T. (2020). Individual differences in behaviour explain

608 variation in survival[?]: A meta-analysis. Ecology Letters, 23(2), 39904408. doi:

$609 \quad 10.1111 /$ ele.13438

610 Nakagawa, S., \& Schielzeth, H. (2010). Repeatability for Gaussian and non-Gaussian data?: A practical

611 guide for biologists. Biological Reviews, 85(4), 9350956. doi: 10.1111/j.1469-

$612 \quad 185 \times .2010 .00141 . x$

613 Niemelä, P. T., \& Dingemanse, N. J. (2018). On the usage of single measurements in behavioural

614 ecology research on individual differences. Animal Behaviour, 145, 990105. doi:

$615 \quad$ 10.1016/j.anbehav.2018.09.012

616 Oosterhoff, L. M. (1977). Variation in growth rate as an ecological factor in the landsnail Cepaea

617 nemoralis (L.). Netherlands Journal of Zoology, 27(1), 10132. doi: 10.1163/002829677X00072

618 Ożgo, M. (2009). Current problems in the research of Cepaea polymorphism. Folia Malacologica,

619 16(2), 55]60. doi: 10.12657/folmal.016.009 
620 Ozgo, M., \& Kinnison, M. T. (2008). Contingency and determinism during convergent contemporary

621 evolution in the polymorphic land snail, Cepaea nemoralis. Evolutionary Ecology Research,

$622 \quad 10,721$ 10733.

623 Ożgo, M., \& Kubea, A. (2005). Humidity and the effect of shell colour on activity of Cepaea nemoralis

624 (Linnaeus, 1758). Folia Malacologica, 13(3).

625 Ożgo, M., Liew, T.-S., Webster, N. B., \& Schilthuizen, M. (2017). Inferring microevolution from

626 museum collections and resampling?]: Lessons learned from Cepaea. PeerJ, 5, e3938. doi:

$627 \quad 10.7717 /$ peerj.3938

Ożgo, M., \& Schilthuizen, M. (2012). Evolutionary change in Cepaea nemoralis shell colour over 43 years. Global Change Biology, 18(1), 74081. doi: 10.1111/j.1365-2486.2011.02514.x

Pedersen, T. L. (2019). patchwork?: The composer of plots. Consulté à l'adresse https://CRAN.Rproject.org/package= patchwork

Petelle, M. B., Martin, J. G. A., \& Blumstein, D. T. (2019). Mixed support for state maintaining risky personality traits in yellow-bellied marmots. Animal Behaviour, 150, 1770188. doi: 10.1016/j.anbehav.2019.02.008

R Core Team. (2020). R: a language and environment for statistical computing (Version 4.0.0). Vienna, Austria: R Foundation for Statistical Computing. Consulté à l'adresse https://www.Rproject.org/

Réale, D., Reader, S. M., Sol, D., McDougall, P. T., \& Dingemanse, N. J. (2007). Integrating animal temperament within ecology and evolution. Biological Reviews, 82(2), 2910318. doi:

Réale, D., Garant, D., Humphries, M. M., Bergeron, P., Careau, V., \& Montiglio, P.-O. (2010). Personality and the emergence of the pace-of-life syndrome concept at the population level. Philosophical Transactions of the Royal Society of London B: Biological Sciences, 365(1560), 4051团4063. doi: $10.1098 /$ rstb. 2010.0208 
645 Richards, P. M., Liu, M. M., Lowe, N., Davey, J. W., Blaxter, M. L., \& Davison, A. (2013). RAD-Seq

646 derived markers flank the shell colour and banding loci of the Cepaea nemoralis supergene.

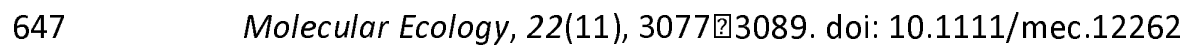

648 Richardson, A. M. M. (1974). Differential climatic selection in natural population of land snail Cepaea

649 nemoralis. Nature, $247(5442)$, 572. doi: 10.1038/247572a0

650 Rosin, Z. M., Kobak, J., Lesicki, A., \& Tryjanowski, P. (2013). Differential shell strength of Cepaea

651 nemoralis colour morphs-Implications for their anti-predator defence.

652 Naturwissenschaften, 100(9), 843]851. doi: 10.1007/s00114-013-1084-8

Rosin, Z. M., Kwieciński, Z., Lesicki, A., Skórka, P., Kobak, J., Szymańska, A., ... Tryjanowski, P. (2018). behaviour of Cepaea nemoralis. The Science of Nature, 105(5), 35. doi: 10.1007/s00114-018$1560-2$

Rosin, Z. M., Lesicki, A., Kwieciński, Z., Skórka, P., \& Tryjanowski, P. (2017). Land snails benefit from human alterations in rural landscapes and habitats. Ecosphere, 8(7), e01874. doi: $10.1002 /$ ecs 2.1874

Rosin, Z. M., Olborska, P., Surmacki, A., \& Tryjanowski, P. (2011). Differences in predatory pressure on terrestrial snails by birds and mammals. Journal of Biosciences, 36(4), 6910699. doi: $10.1007 /$ s12038-011-9077-2

Royauté, R., Berdal, M. A., Garrison, C. R., \& Dochtermann, N. A. (2018). Paceless life? A metaanalysis of the pace-of-life syndrome hypothesis. Behavioral Ecology and Sociobiology, 72(3), 64. doi: $10.1007 /$ s00265-018-2472-z

Santostefano, F., Wilson, A. J., Niemelä, P. T., \& Dingemanse, N. J. (2017). Behavioural mediators of genetic life-history trade-offs[?: A test of the pace-of-life syndrome hypothesis in field crickets. Proc. R. Soc. B, 284(1864), 20171567. doi: 10.1098/rspb.2017.1567

Schielzeth, H. (2010). Simple means to improve the interpretability of regression coefficients. Methods in Ecology and Evolution, 1(2), 103囵113. doi: 10.1111/j.2041-210X.2010.00012.x 
671 Schilthuizen, M. (2013). Rapid, habitat-related evolution of land snail colour morphs on reclaimed

$672 \quad$ land. Heredity, 110(3), 247-252.

673 Seaman, B., \& Briffa, M. (2015). Parasites and personality in periwinkles (Littorina littorea)]: Infection

674 status is associated with mean-level boldness but not repeatability. Behavioural Processes,

$675 \quad 115,132$ 134. doi: 10.1016/j.beproc.2015.03.014

676 Sih, A., Bell, A. M., Johnson, J. C., \& Ziemba, R. E. (2004). Behavioral syndromes[?]: An integrative

677 overview. The Quarterly Review of Biology, 79(3), 241[277. doi: 10.1086/422893

Sih, A., Mathot, K. J., Moirón, M., Montiglio, P.-O., Wolf, M., \& Dingemanse, N. J. (2015). Animal personality and state-behaviour feedbacks?]: A review and guide for empiricists. Trends in Ecology \& Evolution, 30(1), 50团60. doi: 10.1016/j.tree.2014.11.004

Silvertown, J., Cook, L., Cameron, R., Dodd, M., McConway, K., Worthington, J., ... Juan, X. (2011). organism. PLOS ONE, 6(4), e18927. doi: 10.1371/journal.pone.0018927 Cepaea nemoralis (Pulmonata?: Helicidae) as viewed by potential avian predators. Die Naturwissenschaften, 100(6), 533]540. doi: 10.1007/s00114-013-1049-y

Tilling, S. M. (1983). An experimental investigation of the behaviour and mortality of artificial and natural morphs of Cepaea nemoralis (L.). Biological Journal of the Linnean Society, 19(1),

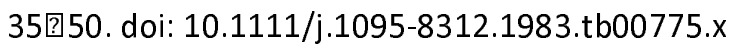
the estimation of repeatabilities and heritabilities?: Issues and solutions. Journal of 
696 Villemereuil, Pierre de, Schielzeth, H., Nakagawa, S., \& Morrissey, M. (2016). General methods for

697 evolutionary quantitative genetic inference from Generalized Mixed Models. Genetics,

698 204(3), 128101294. doi: 10.1534/genetics.115.186536

699 Webster, M. M., \& Rutz, C. (2020). How STRANGE are your study animals? Nature, 582(7812),

700 3370340. doi: 10.1038/d41586-020-01751-5

701 Welter-Schultes, F. (2012). European non-marine molluscs, a guide for species identification.

702 Göttingen: Planet Poster Editions.

703 Wickham, H., Averick, M., Bryan, J., Chang, W., McGowan, L., François, R., ... Yutani, H. (2019).

704 Welcome to the Tidyverse. Journal of Open Source Software, 4(43), 1686. doi:

$705 \quad 10.21105 /$ joss. 01686

706 Wilson, A. J. (2018). How should we interpret estimates of individual repeatability? Evolution Letters,

$707 \quad 2(1), 4$ ? 2 . doi: $10.1002 /$ evl3.40

708 Wolda, H. (1967). The effect of temperature on reproduction in some morphs of the landsnail

709 Cepaea nemoralis (L.). Evolution, 21(1), 1170129. doi: 10.1111/j.1558-5646.1967.tb00135.x

710 Wolf, M., \& McNamara, J. M. (2012). On the evolution of personalities via frequency-dependent

711 selection. The American Naturalist, 179(6), 679?692. doi: 10.1086/665656

712 Wolf, M., \& Weissing, F. J. (2010). An explanatory framew ork for adaptive personality differences.

713 Philosophical Transactions of the Royal Society B: Biological Sciences, 365(1560), 3959@3968.

714 doi: $10.1098 /$ rstb.2010.0215

715 Wright, J., Bolstad, G. H., Araya-Ajoy, Y. G., \& Dingemanse, N. J. (2019). Life-history evolution under

716 fluctuating density-dependent selection and the adaptive alignment of pace-of-life

717 syndromes. Biological Reviews, 94(1), 230?247. doi: 10.1111/brv.12451

718

719 
Tables

721 Table 1: Estimated fixed effect parameters of the model explaining exploration and boldness

722 latencies (mean and 95\% credible intervals). Continuous explanatory variables are centered and

723 scaled, and categorical variables converted to centered dummy variables; the intercept then refers to

724 the behavior of a hypothetical "average" snail.

Mean effect (95\% credible interval)

Exploration Boldness

Fixed effects: main effects

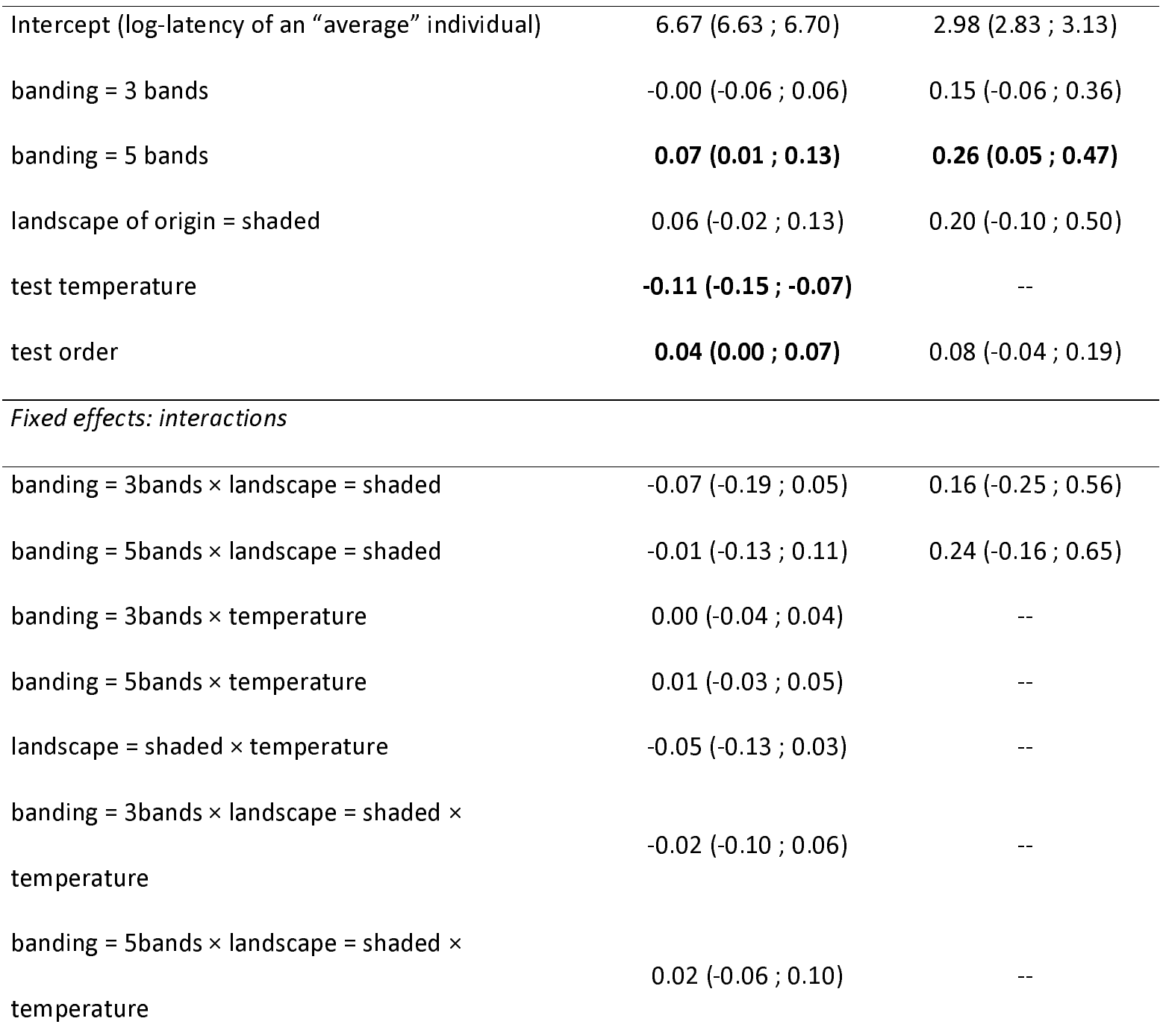


Table 2. Variance partitioning and repeatabilities. Estimated variances and $95 \%$ credible interval are

727 obtained from a multivariate mixed model. Variances are estimated on the observed scale sensu de

728 Villemereuil et al (2016). Variances are rounded to the nearest unit. Readers looking at the data may

729 note that the total variances $V_{p}$ are higher than the empirically observed variances. This is because

730 the latter are underestimated, due to censoring.

\begin{tabular}{lcc}
\cline { 2 - 2 } & \multicolumn{2}{c}{ Posterior mean $(95 \%$ credible interval) } \\
\cline { 2 - 3 } & \multicolumn{1}{c}{ Exploration } & \\
\hline Variance partitioning (observed scale, & in sec $\left.^{2}\right)$ & \\
\hline Fixed effects $V_{F}$ & $13556(6349 ; 21112)$ & $49(6 ; 110)$ \\
- explained by state & $2185(329 ; 4360)$ & $46(4 ; 105)$ \\
Among boxes $V_{B}$ & $8468(2984 ; 15132)$ & $128(12 ; 307)$ \\
- random intercept only & $3102(0 ; 7101)$ & $128(12 ; 307)$ \\
Among individuals $V_{I}$ & $25677(17966 ; 33628)$ & $542(263 ; 875)$ \\
- random intercept only & $24346(17322 ; 32035)$ & $542(263 ; 875)$ \\
Residual $V_{D}$ & $73976(63439 ; 84520)$ & $1795(966 ; 2816)$ \\
\hline Total variance $V_{P}$ & $121676(102632 ; 141659)$ & $2513(1334 ; 3960)$ \\
\hline Repeatabilities (observed scale) & $0.92(0.84 ; 0.98)$ & $0.92(0.84 ; 0.99)$ \\
\hline$R_{\text {(within-state) }}$ & $0.20(0.15 ; 0.25)$ & $0.22(0.15 ; 0.29)$ \\
$R_{\text {(total) }}$ & $0.22(0.17 ; 0.27)$ & $0.24(0.17 ; 0.31)$ \\
\hline$R_{\text {(within-state) }} R_{\text {(total) }}$ & & \\
\hline & & \\
\hline
\end{tabular}

731

732 
bioRxiv preprint doi: https://doi.org/10.1101/866947; this version posted December 14,2020 . The copyright holder for this preprint (which was not certified by peer review) is the author/funder, who has granted bioRxiv a license to display the preprint in perpetuity. It is made available under ACC-BY-NC 4.0 International license.

733 Table 3. Random effect correlation matrices (latent scale, mean and 95\% credible intervals). Box-

734 level correlations are above the diagonal, individual-level correlations below the diagonal.

\begin{tabular}{lccc}
\hline & Boldness, intercept & Exploration, intercept & Exploration, temperature slope \\
\hline Boldness, intercept & & $0.12(-0.42 ; 0.63)$ & $0.38(-0.05 ; 0.79)$ \\
Exploration, intercept & $\mathbf{0 . 2 8 ( 0 . 1 0 ; 0 . 4 6 )}$ & $-0.19(-0.69 ; 0.33)$ \\
Exploration, & & \\
temperature slope & $-0.19(-0.67 ; 0.32)$ & $0.29(-0.24 ; 0.76)$ & \\
\end{tabular}

735

736 


\section{Figure legends}

738 Figure 1. Study species and sites. (A) An unbanded yellow Cepaea nemoralis, showing the position of

739 individual paint marks on the shell (B) Representative shells of the three studied morphs as seen

740 from above: yellow unbanded, three-banded, and five-banded snails (C) Study sites location in

741 France; the open habitat (D) and the shaded habitat (E) are separated by about $2 \mathrm{~km}$. Photographs

742 were taken during winter, when snails were collected.

743 Figure 2. (A; B) posterior distributions of median boldness (A) and exploration (B) in relation to shell

744 morph. The model estimates the mean log-latencies, which correspond to the medians on the

745 observed latencies scale. (C) Mean and 95\% credible band for the relationship between exploration

746 latency and test temperature. Grey lines connect trials from the same individual. Values are plotted

747 on a log-transformed axis. $\mathrm{N}=360$ individuals ( 60 per landscape $\times$ morph combination)

748 Figure 3. Mean (points) and posteriors for the proportion of variance explained by the different

749 variance components. For boldness, $V_{B}$ and $V_{B(\text { intercept) }}$ are exactly equal by definition (same for $V_{I}$ and

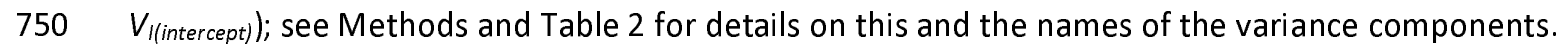

751 Figure 4. Correlation between individual-level random effects for boldness and exploration,

752 illustrated by plotting their respective Best Linear Unbiased Predictors and 95\% credible intervals.

753 Inset: posterior distribution of the correlation coefficient. BLUPS are plotted, and correlation

754 estimated, on the latent log scale. 


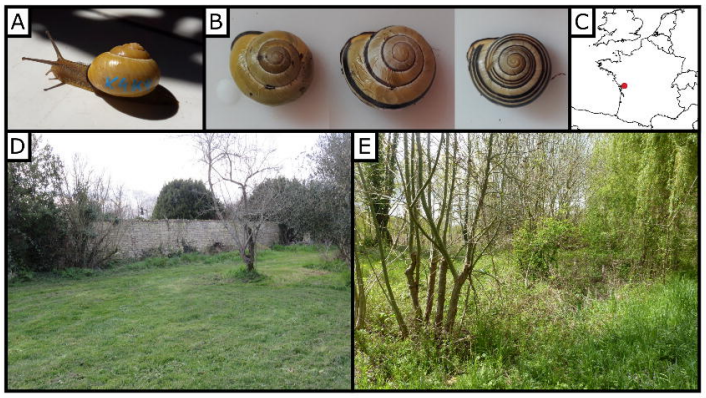



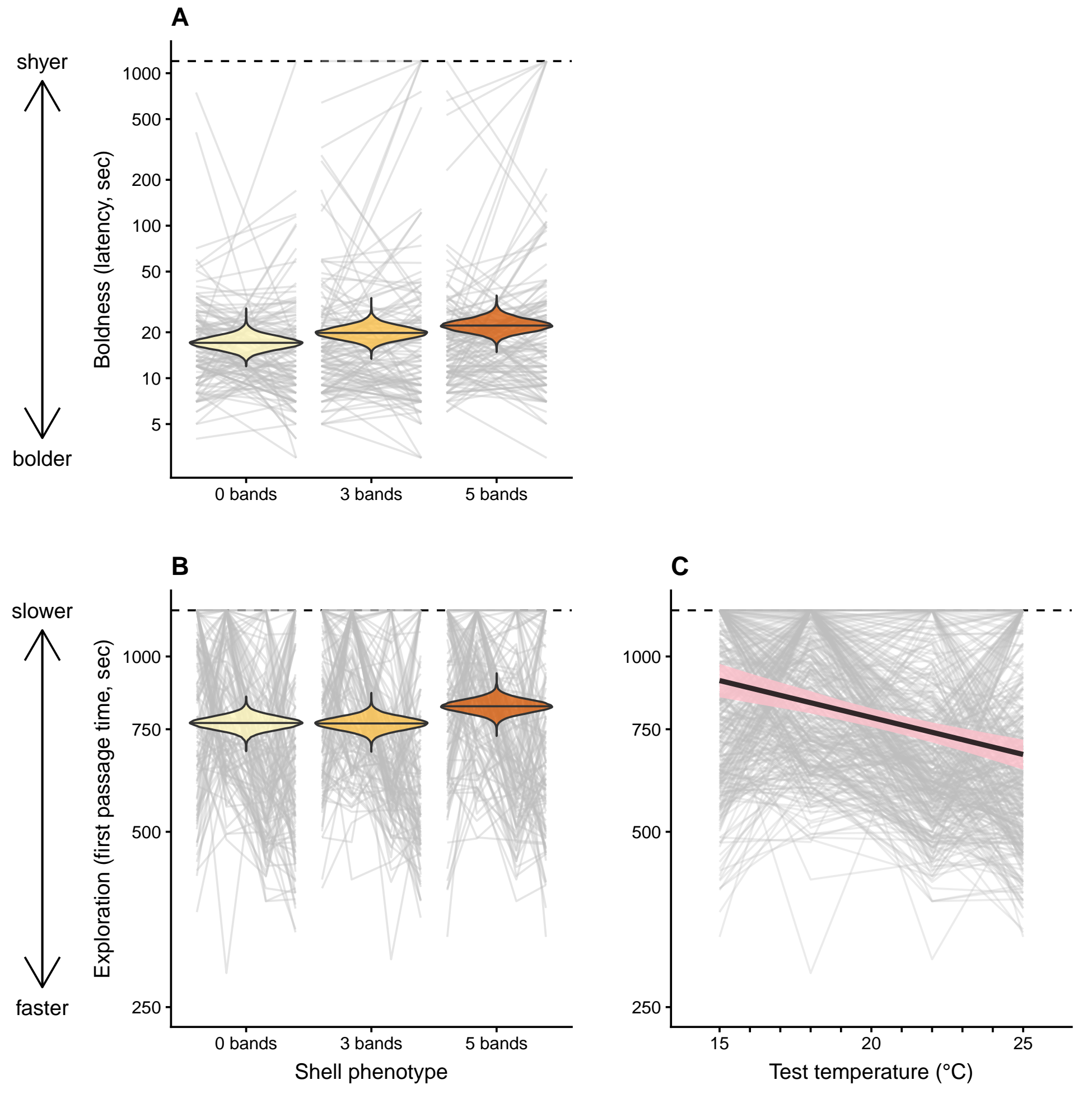


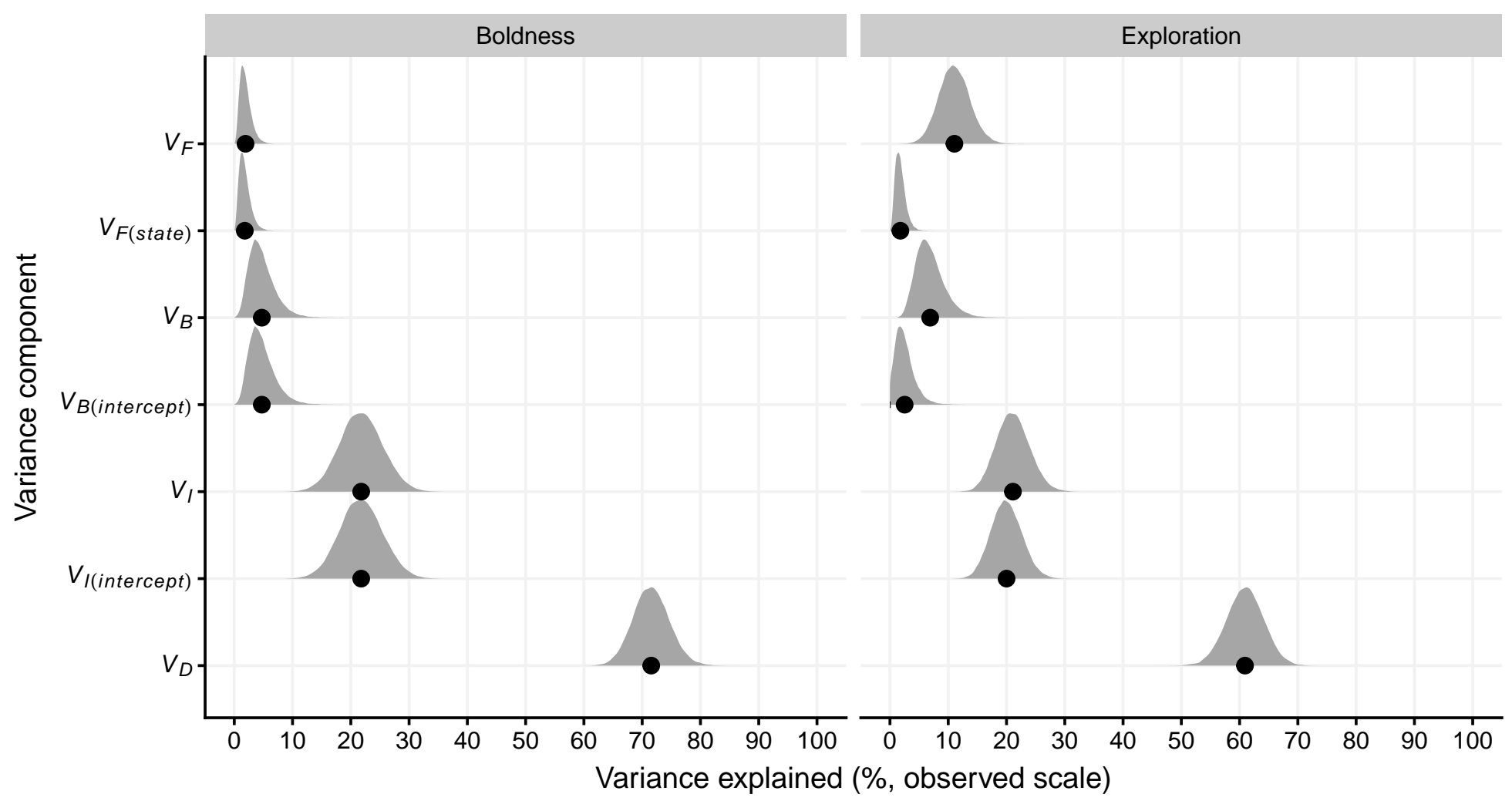


slower

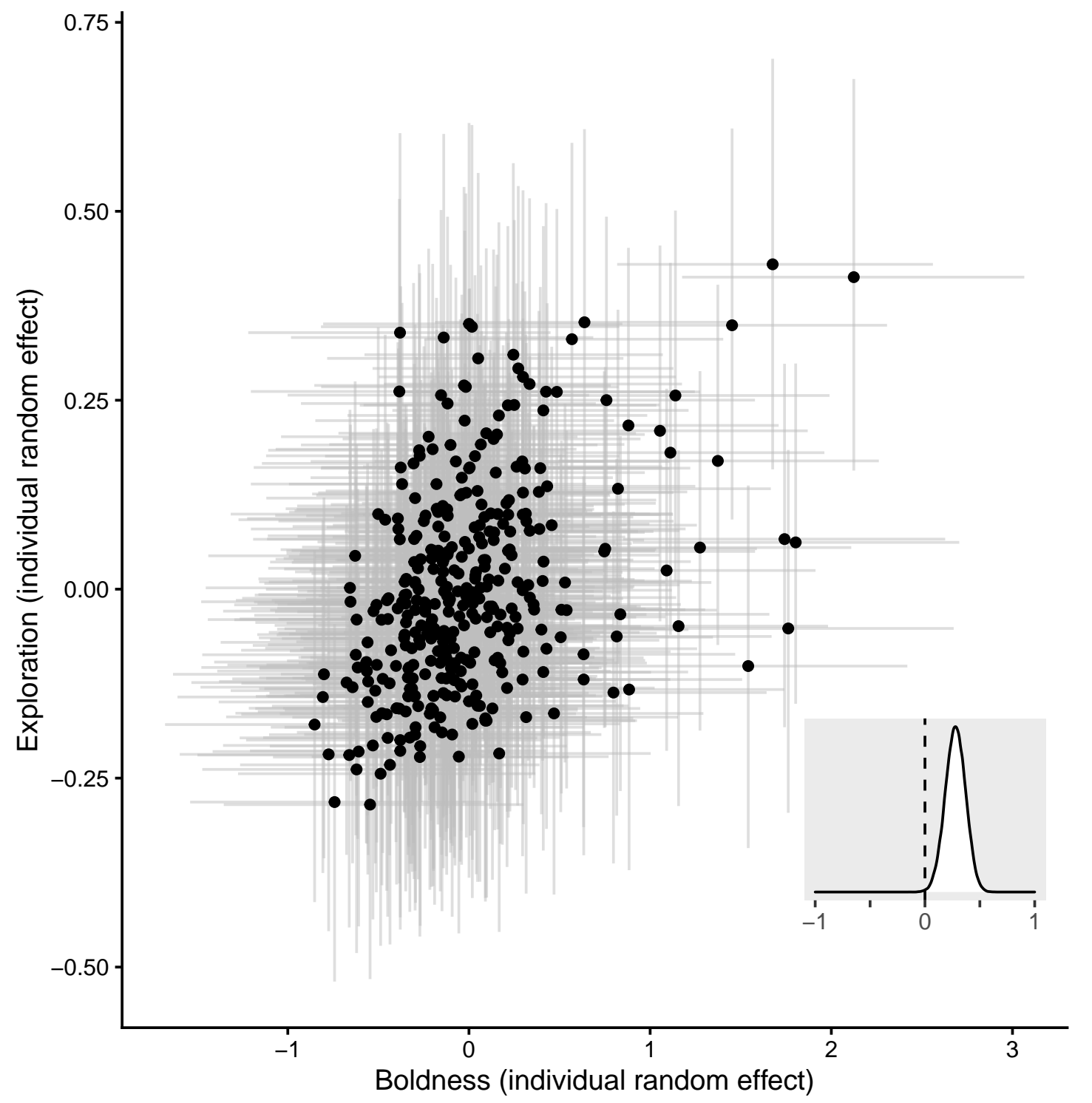

faster

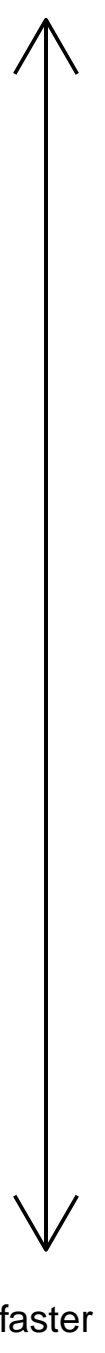

bolder $<$ 